\title{
Study of the Mechanical Behaviour of a Zr-Based Metallic Glass Rod Using Micro- and Nano-Indentation
}

\author{
J. Sort ${ }^{*}, 1$, N. Van Steenberge ${ }^{2}$, A. Gimazov ${ }^{2}$, A. Concustell ${ }^{2}$, S. Suriñach ${ }^{2}$, A. Gebert ${ }^{3}$, J. Eckert $^{4,5}$ and \\ M.D. Baró ${ }^{2}$
}

\author{
${ }^{I}$ Institució Catalana de Recerca i Estudis Avançats (ICREA) and Departament de Física, Facultat de Ciències, \\ Edifici Cc, Universitat Autònoma de Barcelona, 08193 Bellaterra, Barcelona, Spain \\ ${ }^{2}$ Departament de Física, Facultat de Ciències, Edifici Cc, Universitat Autònoma de Barcelona, 08193 Bellaterra, \\ Barcelona, Spain \\ ${ }^{3}$ IFW Dresden, Institute for Metallic Materials, P.O. Box 2700 16, D-01171, Dresden, Germany \\ ${ }^{4}$ IFW Dresden, Institute for Complex Materials, P.O. Box 2700 16, D-01171, Dresden, Germany \\ ${ }^{5}$ TU Dresden, Institute of Materials Science, D-01062 Dresden, Germany
}

\begin{abstract}
The mechanical properties of a $\mathrm{Zr}_{55} \mathrm{Cu}_{30} \mathrm{Al}_{10} \mathrm{Ni}_{5}$ metallic glass rod are investigated by Vickers microhardness and depth-sensing nanoindentation. The alloy exhibits a relatively large hardness which decreases when increasing the maximum applied load. Serrated flow is also observed during nanoindentation. Both effects are related to deformationinduced mechanical softening.
\end{abstract}

Keywords: Bulk metallic glass, nanoindentation, indentation size effect, shear bands, mechanical softening.

\section{INTRODUCTION}

Metallic glasses (MGs) are a particular class of metallic alloys with no long-range atomic order. Due to their amorphous character and the concomitant lack of grain boundaries and dislocations, these materials show unique mechanical properties. For example, they can be twice as strong as steels, exhibit more elasticity and fracture toughness than ceramics and are less brittle than conventional oxide glasses [1-3]. Although the first MGs appeared in form of ribbons in 1960 [4], the first bulk MGs, consisting of spheres with 0.5 $\mathrm{mm}$ in diameter, were developed in 1969 by Chen and Turnbull [5]. In spite of their large elasticity and hardness, MGs exhibit poor room-temperature macroscopic plasticity compared to polycrystalline metals. This low plastic deformability is related to the formation and rapid propagation of shear bands [6-11].

Nevertheless, although the lack of plasticity limits macroscopic applications of MGs, it has been recently shown that premature fracture due to shear band formation can be to some extent inhibited in samples with small sizes [12-15]. This has triggered the recent development of novel types of micro- and nano-electromechanical (MEMS/NEMS) devices based on MGs, such as cantilevers [16], spring actuators [17] or hinges [18]. This trend towards miniaturization has prompted the development of new techniques to characterize the different properties of materials. Amongst these techniques, nanoindentation has revealed itself as a powerful method for testing the mechanical behaviour at the submicron scale [19-22]. This technique is not restricted to materials with small dimensions but it is also used to characterize

*Address correspondence to this author at the Dept. de Física, Universitat Autònoma de Barcelona, 08193 Bellaterra, Spain; E-mail: jordi.sort@uab.es bulk materials, particularly when they show brittle behavior, i.e., when they may exhibit premature failure during macroscopic tensile tests. In this sense, nanoindentation can be considered as a non-destructive technique.

In conventional indentation techniques, like Vickers microhardness, the hardness evaluation involves direct imaging of the residual area. Conversely, during depth-sensing nanoindentation both the applied load and the penetration depth are recorded during the test. This data is then used to determine the mechanical properties, following different procedures such as the method of Oliver and Pharr [20].

In this article, we report on our recent results on the mechanical characterization of a $\mathrm{Zr}_{55} \mathrm{Cu}_{30} \mathrm{Al}_{10} \mathrm{Ni}_{5}$ MG by Vickers microhardness and nanoindetation testing. Microindentation experiments reveal that the Vickers hardness is rather constant along the rod radius. Nanoindentation tests show that the hardness actually depends on the applied load, tending to decrease for higher maximum loads, a result which is interpreted as being due to a deformation-induced mechanical softening of the glass. Other features, such as the occurrence of pop-in events in the loading segments, particularly observed at low loading rates, and the formation of shear bands are also described.

\section{EXPERIMENTAL DETAILS}

A master alloy with composition $\mathrm{Zr}_{55} \mathrm{Cu}_{30} \mathrm{Al}_{10} \mathrm{Ni}_{5}$ (at. \%) was prepared by arc-melting a mixture of high purity (99.9 wt. \%) elements in an Ar atmosphere. Rods of $2 \mathrm{~mm}$ diameter and $10 \mathrm{~cm}$ length were obtained from the arc-melt by copper mould casting. The sample was structurally characterized by X-ray diffraction (XRD), using a Phillips instrument and $\mathrm{Cu}-\mathrm{K} \alpha$ radiation. The thermal stability of the system was investigated using a Perkin-Elmer differential scanning calorimetry (DSC). 
Vickers microhardness tests (using four-sided pyramidal diamond tips) were performed at room temperature, along several radii of the rod, applying a load of $1 \mathrm{~N}$ with a MTH indenter attached to a Zeiss optical microscope. Depthsensing nanoindentation experiments were carried out in the load control mode using a Berkovich three-sided pyramidalshaped tip mounted in a MTS nanoindenter. Prior to indentation, the samples were cut into disks of approximately $1 \mathrm{~mm}$ thickness and carefully polished to mirror-like appearance using diamond paste. The nanoindentation function consisted of a loading segment of $40 \mathrm{~s}$, followed by a load holding segment of $30 \mathrm{~s}$ and an unloading segment of $10 \mathrm{~s}$. The maximum applied loads ranged between 4 and $500 \mathrm{mN}$. The thermal drift was kept below $\pm 0.05 \mathrm{~nm} \mathrm{~s}^{-1}$. From the loaddisplacements curves, the hardness values were evaluated at the end of the load holding segments using the method of Oliver and Pharr, which estimates the hardness as the ratio between the applied load and the contact area [20]. In turn, the contact area between the diamond indenter and the specimen depends on the contact depth, which is determined from the maximum depth at the end of the load holding segment and the stiffness. Proper calibration of the contact area was performed using a fused-quartz standard material. In addition, the continuous stiffness method (CSM) was employed to estimate the dynamic hardness during nanoindentation. In brief, this method consists in applying a small oscillation to the force signal at a relatively high frequency, so that the stiffness can be continuously evaluated during loading $[23,24]$. A maximum load of $450 \mathrm{mN}$ was applied for the CSM measurements. For all indentation conditions, at least ten tests were performed to achieve good statistical results. Images of the indents were obtained both with an optical microscope and a JEOL scanning electron microscope (SEM).

\section{STRUCTURE AND THERMAL STABILITY OF THE $\mathrm{Zr}_{55} \mathrm{Cu}_{30} \mathrm{Al}_{10} \mathbf{N i}_{5}$ METALLIC GLASS}

The XRD pattern recorded for the Zr-based MG is shown in Fig. (1). The pattern consists of broad halos with absence of well-defined peaks, indicating that the rods are amorphous without detectable crystalline phases.

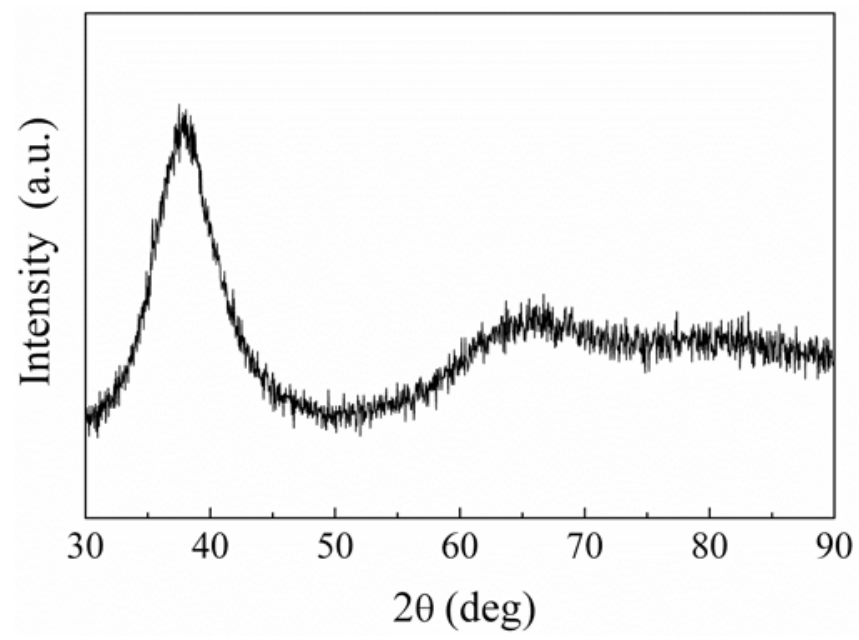

Fig. (1). X-ray diffraction pattern recorded on the $\mathrm{Zr}_{55} \mathrm{Cu}_{30} \mathrm{Al}_{10} \mathrm{Ni}_{5}$ metallic glass.

Further evidence for the amorphous character of the sample is obtained from the DSC scans, as the one shown in
Fig. (2). The curve reveals the existence of a broad exothermic peak at low temperatures, which corresponds to the enthalpy release during structural relaxation. For the heating rate of $40 \mathrm{~K} / \mathrm{min}$, the glass transition temperature is $T_{g}=695$ $K$. Furthermore, two crystallization peaks are observed at $T_{x 1}$ $=778 \mathrm{~K}$ and $\mathrm{T}_{\mathrm{x} 2}=942 \mathrm{~K}$, yielding a supercooled liquid region $\Delta \mathrm{T}=\mathrm{T}_{\mathrm{x} 1}-\mathrm{T}_{\mathrm{g}}=83 \mathrm{~K}$. The crystallization enthalpy, evaluated from the area of the first crystallization peak, is $\Delta \mathrm{H}_{1}=53 \mathrm{~J} / \mathrm{g}$. XRD analysis of the fully crystallized sample (not shown) reveals that the main phases that form upon heating are tetragonal $\mathrm{CuZr}_{2}$, cubic $\mathrm{Al}_{15} \mathrm{Ni}_{8} \mathrm{Zr}_{6}$, orthorhombic $\mathrm{Ni}_{10} \mathrm{Zr}_{7}$ and hexagonal $\mathrm{Al}_{2} \mathrm{Zr}$ phases.

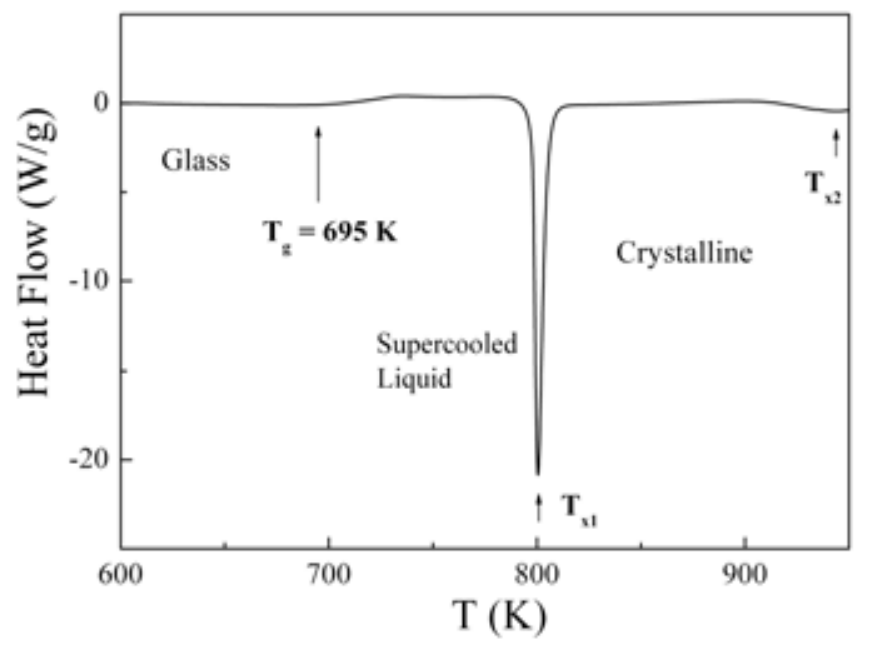

Fig. (2). Differential scanning calorimetry curve of the $\mathrm{Zr}_{55} \mathrm{Cu}_{30} \mathrm{Al}_{10} \mathrm{Ni}_{5}$ metallic glass, recorded during heating from room temperature at a rate of $40 \mathrm{~K} / \mathrm{min}$. The glass transition, $\mathrm{T}_{\mathrm{g}}$, and two crystallization temperatures, $\mathrm{T}_{\mathrm{x} 1}$ and $\mathrm{T}_{\mathrm{x} 2}$, are indicated in the figure.

\section{MECHANICAL PROPERTIES OF THE $\mathrm{Zr}_{55} \mathrm{Cu}_{30} \mathrm{Al}_{10} \mathrm{Ni}_{5}$ METALLIC GLASS}

Vickers microhardness, $\mathrm{H}_{\mathrm{V}}$, tests, carried out along several radii of the rods, allow a three-dimensional hardness map of their cross-section to be depicted. This is shown in Fig. (3). The $\mathrm{H}_{\mathrm{V}}$ values range from approximately $5 \mathrm{GPa}$ to 5.3 GPa, tending to be slightly higher at the centre of the disks. The lack of a pronounced variation in the $\mathrm{H}_{\mathrm{V}}$ values is indicative of the good structural homogeneity of the sample. The slight increase of $\mathrm{H}_{\mathrm{V}}$ at the disk centre is probably related to the cooling rate gradient existing during $\mathrm{Cu}$-mould casting. Namely, the higher cooling rates achieved at the edge of the rod can freeze more free volume in the glass structure and, as a result, the material becomes somewhat softer [25].

To get deeper insight into the mechanical behaviour of the $\mathrm{Zr}_{55} \mathrm{Cu}_{30} \mathrm{Al}_{10} \mathrm{Ni}_{5} \mathrm{MG}$, depth sensing nanoindentation experiments were also carried out. Two load-displacement curves, corresponding to maximum loads of $4 \mathrm{mN}$ and 500 $\mathrm{mN}$ are shown in Fig. (4a) and Fig. (4b), respectively.

It is noteworthy that while some pop-in events are clearly observed for the maximum load of $4 \mathrm{mN}$ [indicated with arrows in Fig. (4a)], such serrations are difficult to detect at higher loads. In particular no serrations are observed when the maximum load is $500 \mathrm{mN}$. It has been suggested that the occurrence of serrated flow during plastic deformation of 


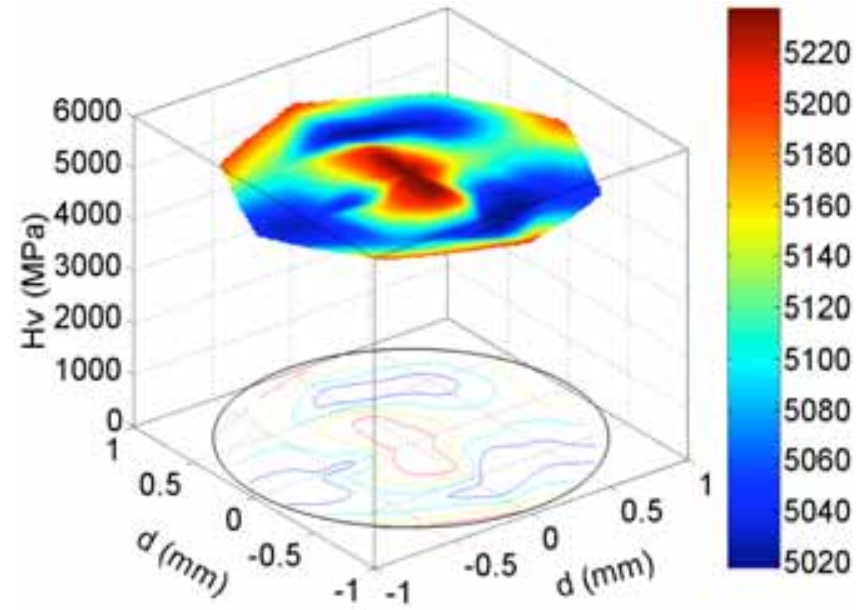

Fig. (3). Three-dimensional mapping of the Vickers microhardness, $\mathrm{H}_{\mathrm{V}}$, across the cross section of the $\mathrm{Zr}_{55} \mathrm{Cu}_{30} \mathrm{Al}_{10} \mathrm{Ni}_{5}$ rods.

MGs depends on the strain rate [26-29]. Lower loading rates result in more pronounced bursts, which are the signature of the formation of shear bands [11]. Since the same loading time has been used in all experiments, independently of the maximum applied load, it turns out that the loading rate is actually higher for higher loads. The higher strain rate when indenting up to $500 \mathrm{mN}$ could thus be the reason for the absence of serrations in Fig. (4b). Nevertheless, SEM images recorded after indenting up to $500 \mathrm{mN}$ reveal the existence of shear bands surrounding the imprints, as it is shown in Fig. (5). Hence, it can be inferred that even if no serrations are seen in the loading curve, shear bands still form during nanoindentation using high loads. Therefore, the lack of serrations in Fig. (4b) is probably due to the limited resolution of the experimental setup rather than the use of exceedingly high loading rates, a possibility which was already put forward by some authors in the literature [10].

Another interesting observation is that the hardness depends on the maximum load used during the nanoindentation tests. This is shown in Fig. (6). Plotted in panel (a) is the dependence of hardness on the maximum load for conventional nanoindentation tests. The same effect can be visualized in panel (b), which shows the dependence of the dynamic hardness on the penetration depth during a measurement using the continuous stiffness method up to a maximum load of $450 \mathrm{mN}$. The hardness in both (a) and (b) decreases from approximately $8 \mathrm{GPa}$ (at $4 \mathrm{mN}$ ) to less than 6.5 $\mathrm{GPa}\left(\right.$ at $500 \mathrm{mN}$ ). Note that the Vickers hardness, $\mathrm{H}_{\mathrm{V}}=5$ $\mathrm{GPa}$, is lower than the hardness evaluated by nanoindentation, probably because of the larger load $(\mathrm{F}=1 \mathrm{~N})$ used for microhardness assessment. This phenomenon, often referred to as indentation size effect (ISE), is usually rather pronounced in single crystalline materials and has been ascribed to a variety of factors, such as surface effects [30], friction between the indenter and the sample [31] or, more recently, strain gradient hardening [32]. The latter considers that, as a result of the shear field created by the indenter, the crystal lattice becomes distorted and, in order to form the residual indentation imprint, so-called geometrically necessary dislocations have to be created. For large indentations, the strain variation between two extremes is more gradual and the statistically stored dislocations can easily accommodate the
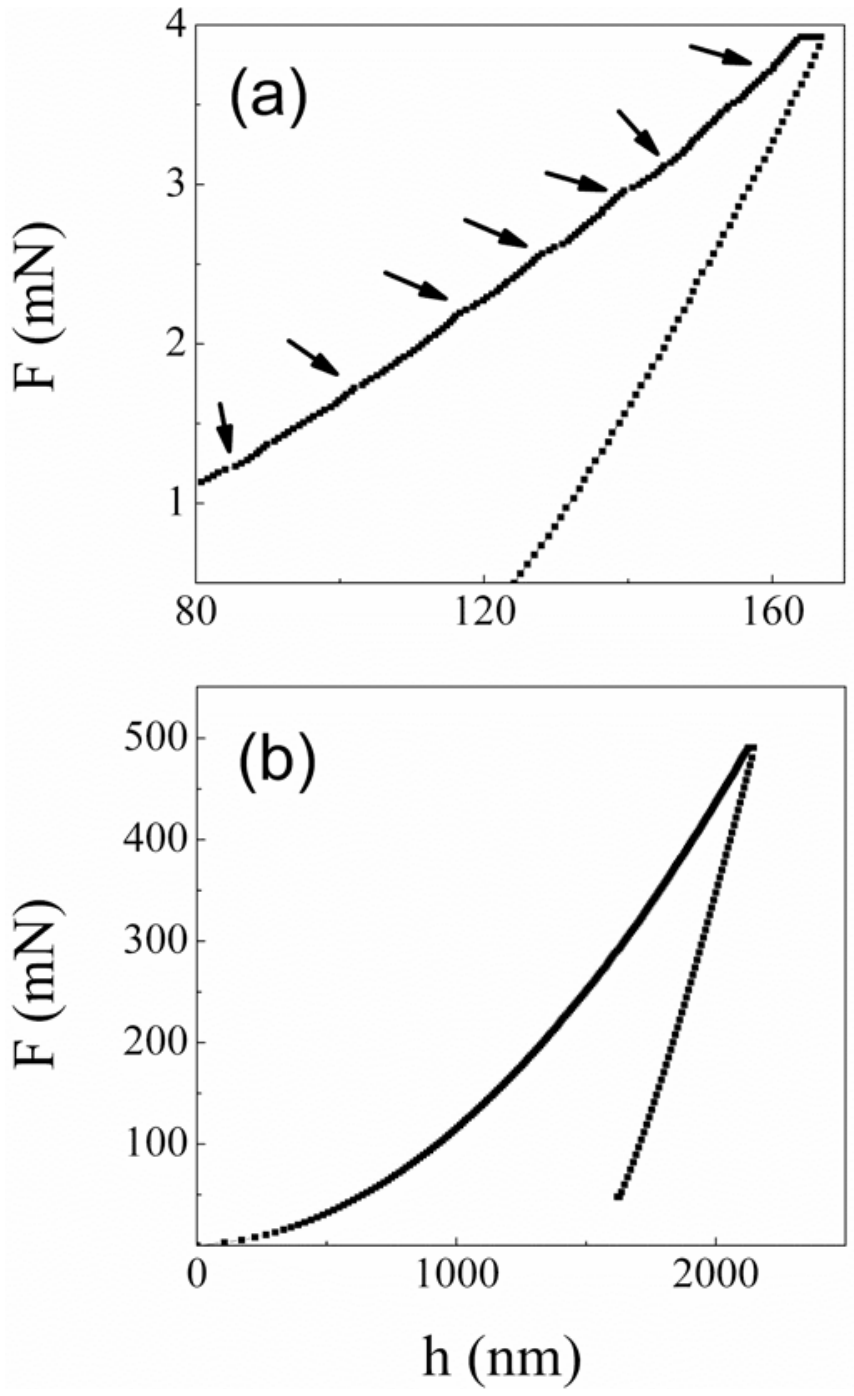

Fig. (4). Load-displacement nanoindention curves of the $\mathrm{Zr}_{55} \mathrm{Cu}_{30} \mathrm{Al}_{10} \mathrm{Ni}_{5}$ rods, with maximum applied loads of (a) $4 \mathrm{mN}$ and (b) $500 \mathrm{mN}$, respectively. Pop-in events in the loading curves are indicated with arrows in panel (a).

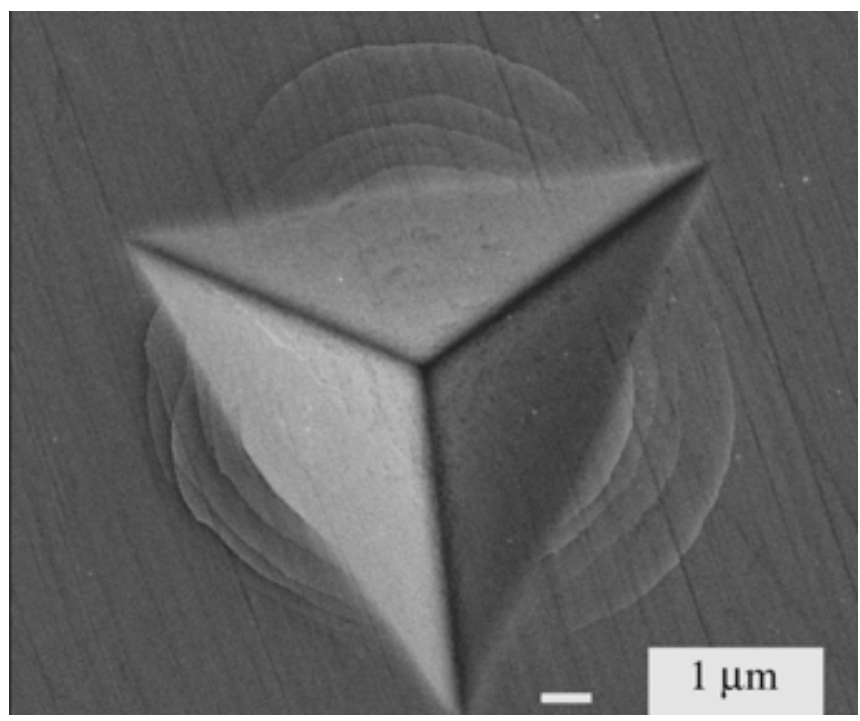

Fig. (5). Scanning electron microscopy image of an indent performed on the $\mathrm{Zr}_{55} \mathrm{Cu}_{30} \mathrm{Al}_{10} \mathrm{Ni}_{5}$ rod applying a maximum load of $500 \mathrm{mN}$. 

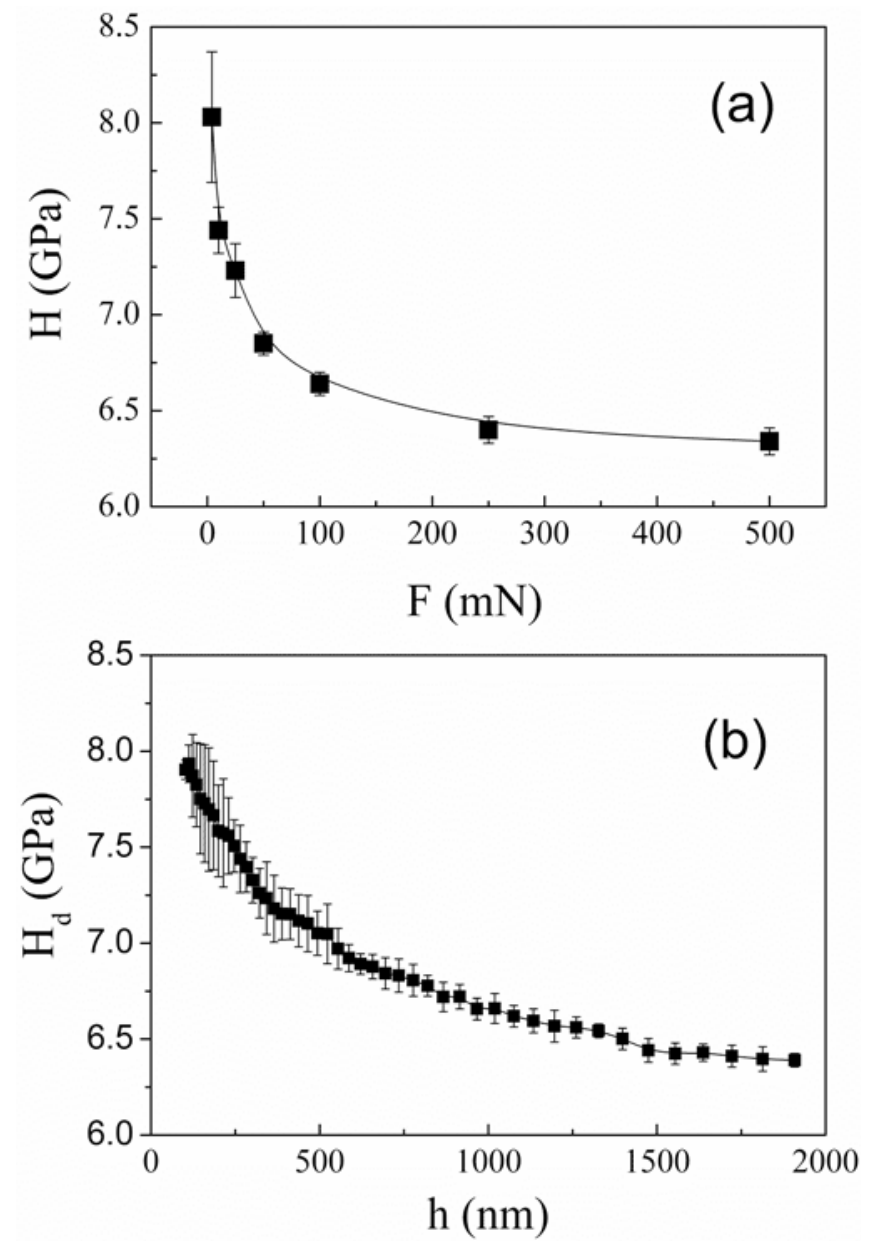

Fig. (6). (a) Dependence of the hardness, H, on the maximum load, $\mathrm{F}$, applied during nanoindentation tests; (b) dependence of the dynamic hardness, $H_{d}$, on the penetration depth, $h$, during measurements using the continuous stiffness method up to a maximum load of $450 \mathrm{mN}$.

shear stress without need of the geometrically necessary dislocations, thus reducing strain gradient effects.

It is noteworthy that, in spite of the lack of dislocations in metallic glasses, the ISE has been also occasionally reported in these systems [33-36]. Its origin is, however, still not well understood. Nevertheless, it has been reported that flow events in MGs are accompanied by dilatation, i.e., creation of free volume $[7,8,37]$. This mechanism results in strain softening during plastic deformation and, hence, it can play a role in the ISE [35,38,39].

From a mechanistic point of view, deformation in MGs occurs via formation of the so-called shear transformation zones [7]. Plastic strain originates from local shear transformations, nucleated under the presence of the applied stress, in specific regions of the material where the amount of free volume surpasses a certain threshold value. These shear transformation zones involve structural rearrangements of groups of 10-20 atoms and result in creation of net free volume which, in turn, promotes the development of further shear transformation events and cause mechanical softening. At high temperatures this process competes with thermallyassisted atomic diffusion and plastic flow is homogeneous throughout the glass. Conversely, at low temperatures (typi- cally lower $0.6 \mathrm{~T}_{\mathrm{g}}$ [7]), accumulation of free volume leads to the formation of shear bands and plastic flow becomes inhomogeneous [7,39]. Since in the $\mathrm{Zr}_{55} \mathrm{Cu}_{30} \mathrm{Al}_{10} \mathrm{Ni}_{5} \mathrm{MG}, \mathrm{T}_{\mathrm{g}}=$ $695 \mathrm{~K}$, room temperature is approximately $0.4 \mathrm{~T}_{\mathrm{g}}$. Therefore, it can be envisaged that plastic flow under ambient conditions will be inhomogeneous, as it has been evidenced by the nanoindentation experiments.

\section{CONCLUSIONS}

Micro- and nano-indentation experiments have been performed in a $\mathrm{Zr}_{55} \mathrm{Cu}_{30} \mathrm{Al}_{10} \mathrm{Ni}_{5}$ metallic glass with the aim of studying its deformation behaviour. The hardness extracted from these tests is found to decrease when increasing the maximum applied load. This result is interpreted as being due to the strain softening that occurs in these glasses during plastic deformation. This softening stems from the development of shear transformation zones which bring about an increase of free volume. At room temperature, the deformation-induced creation of free volume cannot be compensated by thermally-assisted structural relaxation and its accumulation leads to the formation of shear bands. These shear bands, which have been observed by scanning electron microscopy, are the reason for the serrated flow perceived in the loading portions of the nanoindentation experiments, particularly when indenting at sufficiently low strain rates.

\section{ACKNOWLEDGEMENTS}

The authors acknowledge the technical support from the Centre Tecnològic de Manresa. NVS and AG are grateful for the financial support provided by the European Union within the framework of the Research Training Network on "Ductile bulk metallic glass composites" (MRTN-CT-2003504692). Partial financial support from DURSI (2005-SGR00401), MEC (MAT 2007-61629), UAB (PNL2006-019) and MRTN-CT-2003-504692 projects is also acknowledged.

\section{REFERENCES}

[1] Greer AL. Metallic Glasses. Science 1995;267:1947-1953.

[2] Johnson WL. Bulk glass-forming metallic alloys: science and technology. MRS Bull 1999; 24: 42-56.

[3] Telford M. The case of bulk metallic glasses. Mater Today 2004; 7: 36.

[4] Klement W, Willens RH, Duwez P. Non-crystalline structure in solidified gold-silicon alloys. Nature 1960; 187: 869-870.

[5] Chen HS, Turnbull D. Formation, stability and structure of palladium-silicon based alloy glasses. Acta Mater 1969; 17: 1021.

[6] Yavari AR, Lewandowski JJ, Eckert J. Mechanical properties of bulk metallic glasses. MRS Bull 2007; 32: 635-638.

[7] Argon AS. Plastic deformation of bulk metallic glasses. Acta Metall 1979; $27: 47-58$.

[8] Spaepen F. Microscopic mechanism for steady-state inhomogeneous flow in metallic glasses. Acta Metall 1977; 25: 407-415.

[9] Donovan PE, Stobbs WM. The structure of shear bands in metallic glasses. Acta Metall 1981; 29: 1419-1436.

[10] Greer AL, Castellero A, Madge SV, Walker IT, Wilde JR. Nanoindentation studies of shear banding in fully amorphous and partially devitrified metallic alloys. Mater Sci Eng A 2004; 375-377: 11821185.

[11] Golovin YI, Ivolgin VI, Khonik VA, Kitagawa K, Tyurin AI. Serrated plastic flow during nanoindentation of a bulk metallic glass. Scripta Mater 2001; 45: 947-952.

[12] Ashby MF, Greer AL. Metallic glasses as structural materials. Scripta Mater 2006; 54: 321-326.

[13] Conner RD, Li Y, Nix WD, Johnson WL. Shear band spacing under bending of Zr-based metallic glass plates. Acta Mater 2004; 52: 2429-2434.

[14] Schroers J, Johnson WL. Ductile bulk metallic glasses. Phys Rev Lett 2004; 93: 255506. 
[15] Zheng Q, Cheng S, Strader JH, Ma E, Xu J. Critical size and strength of the best bulk metallic glass former in the $\mathrm{Mg}-\mathrm{Cu}-\mathrm{Gd}$ ternary system. Scripta Mater 2007; 56: 161-164.

[16] Liu YD, Hata S, Wada K, Shimokohbe A. Thermal, mechanical and electrical properties of Pd-based thin-film metallic glass. Jpn J Appl Phys 2001; 40: 5382-5388.

[17] FukushigeT, Hata S, Shimokohbe A. A MEMS conical spring actuator array. J Microelectromech Sys 2005; 14: 243-253.

[18] Tregilgas JH. EMAA Winner: Amorphous Titanium Aluminide Hinge. Adv Mater Proc 2004; 162: 40.

[19] Fischer-Cripps AC. Nanoindentation, Springer-Verlag Inc.: New York: 2002

[20] Oliver WC, Pharr GM. An improved technique for determining hardness and elastic modulus using load and displacement senseing indentation experiments. J Mater Res 1992; 7: 1564-1583.

[21] Schuh CA. Nanoindentation studies of materials. Mater Today 2006; 9: 32-40.

[22] Li X D, Bhushan B. A review of nanoindentation continuous stiffness measurement technique and its applications. Mater Charact 2002; 48: 11-36

[23] Mukhopadhyay NK, Paufler P. Micro- and nanoindentation techniques for mechanical characterisation of materials. Internat Mater Rev. 2006; 51: 209-245.

[24] http://www.mtsnano.com/products/csm/

[25] Huang YJ, Shen J, Sun JF. Bulk metallic glasses: Smaller is softer. Appl Phys Lett 2007; 90: 081919.

[26] Schuh CA, Lund AC, Nieh TG. New regime of homogeneous flow in the deformation map of metallic glasses: elevated temperature nanoindentation experiments and mechanistic modeling Acta Mater 2004; 52: 5879-5891.

[27] Jiang WH, Atzmon M. Rate dependence of serrated flow in a metallic glass. J Mater Res 2003; 18: 755-757.

[28] Schuh CA, Nieh TG, Kawamura Y. Rate dependence of serrated flow during nanoindentation of a bulk metallic glass. J Mater Res 2002; 17: 1651-1654.
[29] Yang B, Nieh TG. Effect of the nanoindentation rate on the shear band formation in an Au-based bulk metallic glass. Acta Mater 2007; 55: 295-300.

[30] Gerberich WW, Tymiak NI, Grunlan JC, Horstemeyer MF, Baskes MI. Interpretations of indentation size effects. J Appl Mech 2002; 69: 433-442.

[31] Li H, Ghosh A, Han YN, Bradt RC. The frictional component of the indentation size effect in low load microhardness testing. J Mater Res 1993; 8: 1028-1032.

[32] Nix WD, Gao H. Indentation size effects in crystalline materials: A law for strain gradient plasticity. J Mech Phys Sol 1998; 46: 411425.

[33] Manika I, Maniks J. Size effects in micro- and nanoscale indentation. Acta Mater 2006; 54: 2049-2056.

[34] Jana S, Ramamurty U, Chattopadhyay K, Kawamura Y. Subsurface deformation during Vickers indentation of bulk metallic glasses. Mater Sci Eng A 2004; 375-377: 1191-1195.

[35] Van Steenberge N, Sort J, Concustell A, et al. Dynamic softening and indentation size effect in a Zr-based bulk glass-forming alloy. Scripta Mater 2007; 56: 605-608.

[36] Zhang HW, Jing X, Subhash G, Kecskes LJ, Dowding RJ. Investigation of shear band evolution in amorphous alloys beneath a Vickers indentation. Acta Mater 2005; 53: 3849-3859.

[37] De Hey P, Sietsma J, Van Den Beukel A. Structural disordering in amorphous Pd40Ni40P20 induced by high temperature deformation. Acta Mater 1998; 46: 5873-5882.

[38] Concustell A, Sort J, Alcalá G, et al. Plastic deformation and mechanical softening of $\mathrm{Pd}_{40} \mathrm{Cu}_{30} \mathrm{Ni}_{10} \mathrm{P}_{20}$ bulk metallic glass during nanoindentation. J Mater Res 2005; 20: 2719-2725.

[39] Bhowmick R, Raghavan R, Chattopadhyay K, Ramamurty U. Plastic flow softening in a bulk metallic glass. Acta Mater 2006; 54: 4221-4228. 